\title{
Challenges in the development of Current Conditions for the Lachlan River, New South Wales
}

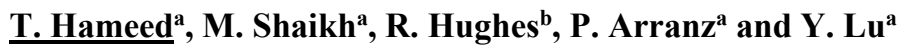 \\ ${ }^{a}$ NSW Department of Industries, 10 Valentine Avenue, Parramatta NSW 2150 \\ ${ }^{b}$ Cardno, 47 Burelli St Wollongong NSW 2500 \\ Email: tahir.hameed@dpi.nsw.gov.au
}

\begin{abstract}
During the development of the surface Water Sharing Plan (WSP), a long-term IQQM computer model scenario run was developed for Lachlan River System to simulate the patterns of water use in the valley over the full climate record (100 plus years) under plan rules and development conditions. The average annual valley-wide extraction simulated in this scenario run represents the 'long-term extraction limit' or 'Plan Limit'.
\end{abstract}

As per WSP, the water use in the valley needs to be tested against the Plan Limit model by operating a parallel long-term model under the development conditions at that point in time generally known as the 'Current Conditions' model. This Current Conditions model is intended to include updated infrastructure information, farm level development (e.g. crop areas and cropping mix) and demand patterns (e.g. entitlement share components and planting decisions). The updated Current Conditions model run is then compared to the Plan Limit model run over the full climate record to determine whether overall extraction has increased or not.

If the Current Conditions average annual extraction significantly exceeds the Plan limit, then the maximum annual use permitted for general security entitlement holders will be reduced. The degree of reduction was the amount just sufficient to keep the Current Conditions extraction within the Plan Limit. At WSP commencement the 'annual use limit' was calculated to be 0.75 (or $75 \%$ ) of entitlement.

The above process is heavily reliant on good quality on-farm data such as planted crop types \& areas and planting decisions. The on farm data that were previously collected on an annual basis are no longer regularly collected on a valley-wide basis. In absence of crop types and planted area data, irrigators' surveys were initiated for the determination of crop types and planted areas. In general the response rate of any survey is quite low and therefore the management of irrigators' surveys is a long exhaustive process. An alternative way of estimation of crop areas is the use of satellite imagery data that can be estimated quickly with relative ease.

This paper describes the methods and processes of estimation of planted crop areas irrigated from surface water and the planting decisions using satellite remote sensing as well as sampled survey data and then comparing with each other. The process of estimating the valley planted areas is a complicated exercise as a significant number of irrigators' have both surface as well as ground water entitlements.

Keywords: Integrated Quantity Quality Model (IQQM), Surface Water Sharing Plan, Current Development conditions, river system modelling, irrigators' surveys 


\section{INTRODUCTION}

Extensive irrigation development has resulted in considerable deterioration of river health of the Murray Darling Basin (the Basin). In early nineties it was recognised that the continuous growth of river diversions needed to be stopped and therefore Murray Darling Basin Authority (MDBA) imposed an upper limit of diversions from the basin to 1993/94 development conditions and operating rules. To comply with the MDBA Cap, Surface as well as Ground Water Sharing Plans of all river systems of the Basin within NSW were developed in early 2000s. Integrated Quantity Quality Model (IQQM) was the primary tool that was used to simulate the patterns of water use over the full climate record under Surface Water Sharing Plan rules and development conditions. The average annual valley-wide extraction simulated in the Surface Water Sharing Plan scenario represents the 'long-term extraction limit' or 'Plan Limit'.

As per WSP, every year the water use in the Lachlan River Valley (the valley) needs to be tested against the Plan Limit model by operating a parallel long-term model under the development conditions at that point in time generally known as the 'Current Conditions' model. This paper only deals with the surface water of Lachlan River System therefore ground water issues are not discussed. This Current Conditions model is intended to include updated infrastructure information, farm level development (e.g. crop areas, cropping mix) and demand patterns (e.g. entitlement share components, planting decisions). The updated Current Conditions model run is then compared to the Plan Limit model run over the full climate record of 100 plus years to determine whether overall extraction has increased or not.

If the Current Conditions average annual extraction significantly exceeds the Plan limit, then the maximum annual use permitted for general security entitlement holders will be reduced. The degree of reduction was the amount just sufficient to keep the Current Conditions extraction within the Plan Limit. At WSP commencement the 'annual use limit' for Lachlan River System was calculated to be 0.75 (or $75 \%$ ) of each entitlement.

In mid-2000s, it was realised that even more flows were needed to maintain the health of the basin. MDBA initiated and completed a number of studies and it was estimated that an extra 3,000 to 4,000 GL of water would be needed for the sustainability of the Basin. After considering various water savings projects and stockholders' consultations it was agreed that 2,750 GL would need to be recovered from the 2009 Baseline Diversion Level (https://www.mdba.gov.au/basin-plan/whats-basin-plan). Therefore it was planned to buy back entitlements equivalent to 2,750GL out of which around 2,000 GL are already bought from the willing entitlement holders. For most of the valleys the Baseline Diversion Limit (BDL) that has similar development and rules as of WSP, is essentially the Plan Limit.

Computer models will be used for the development of valley-based updated water sharing plans for all river valleys to make sure that NSW will stay within Sustainable Diversion Limit (SDL; which is BDL minus buybacks) and for checking each year if the valleys are complying. The most recent development scenario (Current Conditions) will be the baseline model for the development of new plan. Although the SDL complying procedure is not determined yet, it is expected that every year the future Current Conditions models would be compared to the model having new plan rules and conditions.

Since the Current Conditions scenario may need to be developed frequently, it is important to establish proper processes and procedures, for consistency and efficiency. This paper describes the challenges faced in the recent current condition scenario for Lachlan river system and looks into how the processes for future scenario development can be streamlined.

\section{IQQM}

IQQM operates on a pseudo-continuous time basis and can be used to simulate river system behavior for periods ranging up to hundreds of years (DLWC, 1995). It is designed to examine long-term behavior under various management regimes which include environmental flow requirements (Hameed \& Podger, 2001). IQQM uses a node-link representation of the river system. Each important feature of a river system is represented by one of the available thirteen node types. The movement and routing of water between nodes is represented by the links. The model is run on a daily time step but it can also be run on hourly time steps as well.

The water quantity module of IQQM simulates all the processes and rules associated with the movement of water through the river system. The major processes include:

- $\quad$ effluent and irrigation channels and flow routing

- $\quad$ water orders, river and reservoir operations 
Hameed et al., Challenges in the development of Current Conditions for the Lachlan River, New South Wale

- water demands and diversions (such as wetlands, crop water, towns, etc.)

- water sharing rules among regulated and unregulated river systems;

- resource assessment and single or multiple water accounting systems

The irrigation module in IQQM is based on soil moisture accounting, decisions of irrigators regarding the crop areas to be planted, irrigation requirements, water ordering and usage. The module takes into account on-farm storage operation where appropriate, and accounts for water use in relation to water entitlements and access rules.

\section{STUDY AREA}

The Lachlan River Valley located in central western NSW occupies around $85,000 \mathrm{~km}^{2}$ which is about $10 \%$ of NSW (Figure 1). The eastern part of the drainage basin has higher elevations of 1000-1400 m and contributes most of the flow to the river. Average rainfall varies from $1200 \mathrm{~mm}$ along the elevated eastern part of the drainage basin to $250 \mathrm{~mm}$ in the lower western reaches. Potential average annual evaporation exceeds average annual rainfall over the entire drainage basin with $1210 \mathrm{~mm} / \mathrm{year}$ evaporation in the east and up to $1750 \mathrm{~mm} /$ year in the west. Lucerne, cotton, wheat and almonds are major crops planted in Lachlan.

The Lachlan is a complex regulated river system having numerous anabranches, several headwater and reregulating storages, wetlands, major irrigation developments, and various environmental needs. There are two headwater storages, Wyangala and Carcoar Dams. The two mid-river storages, Lake Cargelligo and Lake Brewster, are used to capture and re-regulate excess water coming from the tributaries located downstream of the headwater storages. In addition, various weirs provide the necessary head for water diversion. River regulation is further complicated by the long travel times for water released from the headwater storages to the furthest water user (approximately four weeks). The standard DPI Water resource assessment procedure is applied in the Lachlan for its continuous accounting system.

Large diversions of water for irrigation and other consumptive purposes have impacted severely on Lachlan River health and wetlands. Some of the major problems are: (a) land clearing and subsequent soil erosion; (b) fewer medium floods as a result of extensive river regulation; (c) reduced river flow to wetlands (d) decline of native fish and increased proliferation of introduced species; and (e) increased salinity and poor water quality.

\section{DATA REQUIREMENTS FOR SETTING UP THE CURRENT CONDITIONS SCENARIO}

To develop the IQQM current condition scenario, information on the following is required:

1. Storage and other infrastructure

2. Farm level maximum current development (e.g. crop areas)

3. Demand patterns (e.g. crop types)

4. Crop Area Decision function

The storage and other infrastructure information are generally available and can be extracted with relative ease. However data on crop areas and crop types are not readily available for the river basin. In the past WaterNSW (previously State Water) used to gather planted crop types and areas annually. However the data collection was discontinued in 2004.

The crop statistics (crop types and planted areas) for 2012/13 water year are considered crucial to developing a long-term Current Conditions model that accurately reflects contemporary irrigation watering patterns. This is because 2012/13 represents the maximum current irrigated crop area for the valley that happened under the maximum possible water allocations. On 1 July 2012, regulated river storages were full and general security water availability was $138 \%$ of entitlement on average. The Lachlan Continuous Accounting rules allow the water availability to be more than $100 \%$ however use limit cannot exceed $100 \%$ in any year. The 2012 spring and summer were hot and dry. This combination lent itself to the planting of large summer crop areas and the use of large volumes of irrigation water. This sets the upper limit on crop development and water use patterns in the Lachlan regulated river as applied to the whole period of climate record.

Irrigators' Crop Area Planting Decision function is essential for setting up of any development scenario. A minimum of 3 years crop data are needed for the development of the decision function. Therefore it was decided to collect crop statistics for at least 3 years. The development of Crop Area Planting Decision is described in more details in the following sections. 


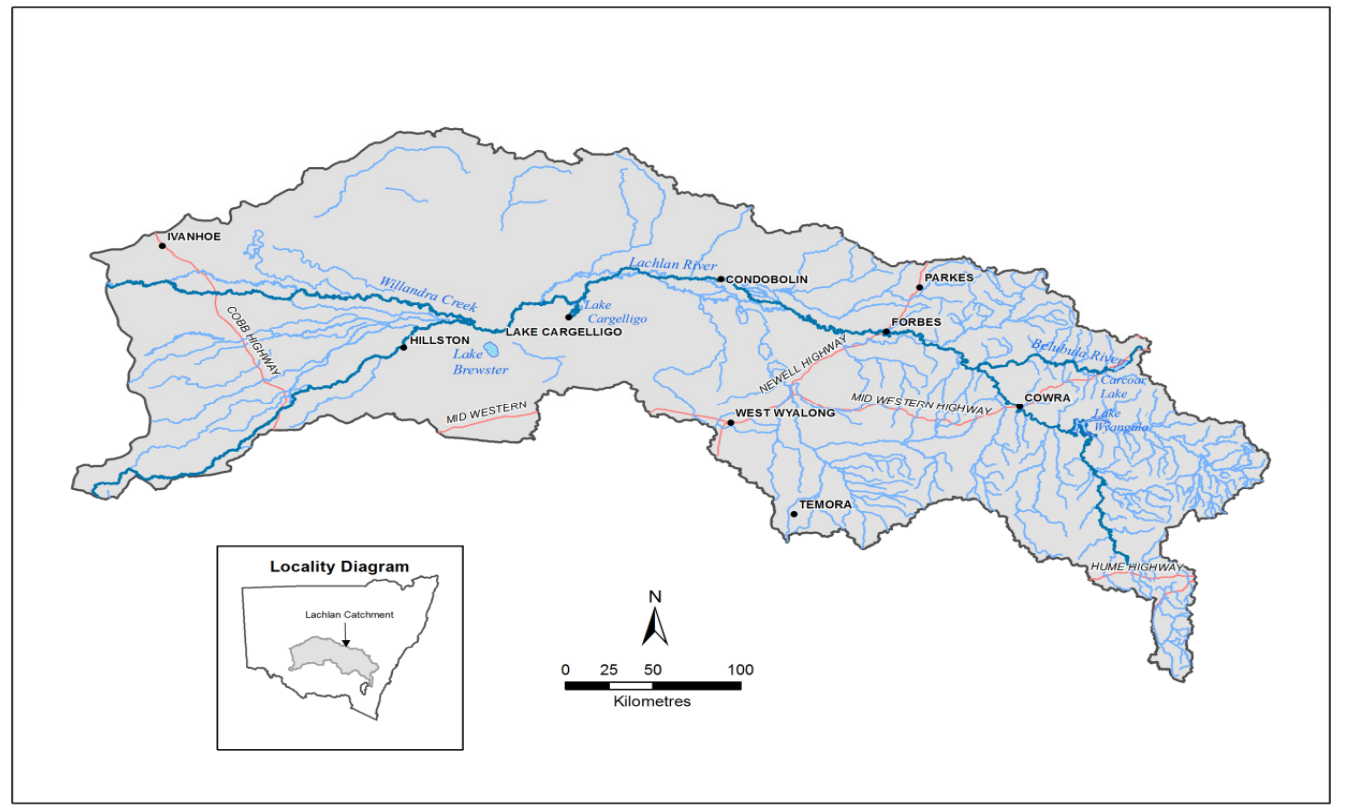

Figure 1. Lachlan River System

\section{CROP DATA COLLECTION AND ANALYSIS}

Following sections describe the methods adopted for collection of crop statistics:

\subsection{Survey Based}

Collecting crop areas and types directly from irrigators, although not most efficient, is still the most direct and logical method. The first survey was initiated in late 2013. The survey was web based and designed to get detailed information for the last few years. The survey provided essential data that enabled developing the Crop Area Planting Decision. The response to the survey was very poor at only about 5.

A subsequent survey was therefore undertaken and sent in December 2013. This was very brief and intended to get only the essential information for the previous year. The simplified survey was sent by mail to 113 irrigators in the Lachlan valley whose water usage in 2011/12 and 2012/13 exceeded 400 ML. This mail-out was followed up by a phone call and users were asked to provide only the crop types and the planted areas for summer and winter of 2012/13. Later on 2 more surveys were sent in 2014 and 2015 for the collection of 2013/14 and 2014/15 crop statistics.

The response to the simpler survey for 2012/13 year was significantly higher, representing around $70 \%$ of total surface water use for irrigation in the valley. This large response rate provides confidence in the data underlying the irrigated crop areas for that year.

The survey responses were then arranged according to IQQM river reaches. Although overall response rate was high, returns for some of the river reaches were very low. The crop areas of the surveyed irrigators were then matched with the respective river and groundwater diversions through their customer number, work approvals and entitlement numbers.

In some of the lower sections of the valley, groundwater had been used to irrigate a proportion of the planted areas reported in the surveys. This is particularly significant in the Willandra Weir to Booligal section. Therefore the first step was to adjust the reported crop areas to represent the areas irrigated by the surface water only.

These adjustments required correct surface water and ground water diversions from the recorded data within DPI Water database. A range of different checks were conducted to estimate accurate diversions: 
1. All historical surface water and linked groundwater diversion data was extracted using a consistent approach for each year (with the intention of using the approach for 3 years) and compared to other reported data sources;

2. This data was separated by river reach and by season (summer and winter), accounting for water use under multiple entitlements and at multiple location of works approval;

3. All sources of non-extractive water use were separated out (i.e. environmental water held on general security and high security entitlements).

Following the above process, the total Lachlan river valley diversion volume for 2012/13 was estimated to $273 \mathrm{GL}$ that was close to the reported range of 270-280 GL. This estimate was considered adequate given there were a number of uncertainties in the databases especially inaccurate High Security diversions. Both surface as well as groundwater diversions for the surveyed irrigators were also estimated following the above procedure.

The groundwater diversions were added to the surface water diversions for each river reach for the entitlements reported in the surveys. The total diversions were then divided by the reported areas to calculate the overall application rates in ML/ha for each reach. Based on those application rates, the surveyed crop areas were then re-adjusted to the surface water irrigated areas only. Consequently the adjusted total combined summer and winter areas were reduced by around 9,000 ha.

After groundwater adjustment, the results were then scaled up to include the remaining diversions that were made by the irrigators who either did not respond or not included in the surveys, to provide estimates of the total crop area for the entire valley. The resultant total crop area estimated to be around 65,000 ha (Figure 2).

Similar to 2012/13 data, the crop area data was re-estimated for the remaining two survey years 2013/14 and $2014 / 15$. Unfortunately the response rate of the questionnaires declined each year from $70 \%$ in $2012 / 13$ to $55 \%$ in $2013 / 14$ and only $30 \%$ in $2014 / 15$. For some of the river reaches the recent survey resulted in no responses or very limited responses which may not be a true representation of water users within that reach. A sensitivity analysis showed that the predicted crop areas for 2013/14 and 2014/15 years can vary anywhere between $10-20 \%$. Therefore it was decided to pay more attention to matching modelled diversions to the recorded diversions for the 2013/14 and 2014/15 years. For those years it was expected that the predicted model areas would not exactly match the recorded areas.

\subsection{Remote Sensing}

Remote sensing methods offer repetitive and synoptic coverage with rapid mapping techniques. This is faster and cost-effective compared to collecting the crop information manually from the irrigators. An objective and repeatable remote sensing and GIS approach has been developed to efficiently identify the irrigated crops based on Landsat imagery. Using entitlement and property information, irrigated type of the cropping area 
can be classified as surface water, groundwater and combination of surface water and groundwater, and finally assigned to each river reaches.

Landsat imagery provides the longest earth monitoring satellite data with more than 30 years of image archives. It has a 30 meter resolution and a 16 day revisit orbit, and the calibrated images are available free of charge. The water year for the purpose of this project is defined as starting with summer; therefore summer 2012/13 images are from October 2012 to March 2013 (Hughes et al, 2015). The Lachlan catchment is covered by approximately eight Landsat images. Image analysis was undertaken by generating Normalised Differentiated Vegetation Index (NDVI) images which

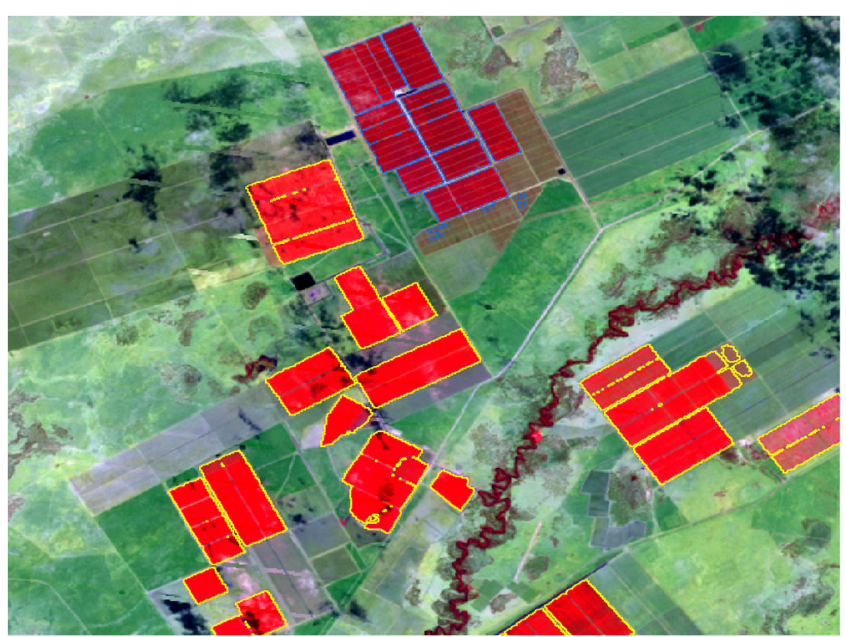

Figure 3. Surface water irrigated areas (red parts outlined by yellow borders; dark red are GW irrigated) were further analysed to extract irrigated areas. Image interpretation was undertaken to further analyse NDVI value range to accurately extract information related to cropping areas by using semi-empirical approaches of the threshold. This process included interpretation of greenness by visually inspecting a number of polygons to assess quality of information and detect all the irrigated area by Surface Water (SW) and Ground Water (GW).

Entitlement and property information from Water Licensing System (WLS) database and surveys are used to classify the irrigated crop by SW or GW categories and summarize the SW irrigated cropping area, GW irrigated cropping area and combination of SW and GW irrigated cropping area based on each river reach. Presence of combined SW and GW entitlements on some properties created difficulties in assigning the cropping areas to the above categories.

The irrigated crop areas were further classified based on Landuse Mapping (Office of Environment and Heritage), which includes Landuse categories such as irrigated cropping, grazing irrigated modified pastures, irrigated perennial horticulture and irrigated seasonal horticulture. Since IQQM crop model keeps track of each crop type therefore estimation of different crops is useful for better model calibration.

Figure 3 shows an example of surface water irrigated areas (red parts outlined by yellow borders) estimated by remote sensing by linking them to individual properties using licensing and works approval data.

\subsection{Comparison of Planted Areas from Survey and Remote Sensing}

The summer crop areas estimated in previous sections by surveys and remote sensing are compared in Table 1 (2014/15 imagery is currently being analysed). As Table 1 shows, areas estimated based on remote sensing were slightly larger. These discrepancies can be due to reasons including the incorrect diversions used for calculating the survey based areas, incorrect entitlements numbers associated with imagery and separation of irrigated surface water areas from ground water.

Table 1: Comparison of Summer Areas (ha) based on Surveys and Remote Sensing

\begin{tabular}{|l|l|l|}
\hline Water Year & Surveys & Remote Sensing \\
\hline $2012 / 13$ & 32,000 & 38,000 \\
\hline $2013 / 14$ & 26,000 & 35,000 \\
\hline
\end{tabular}

\subsection{Crop Area Planting Decision}

One source of uncertainty in the Lachlan IQQM is the irrigators' Crop Area Planting Decision which relates planted crop area to water availability. To develop a Crop Area Planting Decision function with a reasonable degree of confidence, at least 4 to 5 data points are typically needed. For present study only 3 points $(2012 / 13,2013 / 14$ and 2014/15) were available. The Crop Area Planting Decision functions were purely based on the 2012/13 maximum area and matching 2012/13, 2013/14 and 2014/15 diversion data. In addition to these, an estimation of the minimum planted area when the General Security (GS) entitlements holders' 
balance is zero, is needed. Following discussion with several large Lachlan irrigators, it was ascertained that irrigators will plant around 10,000 ha even with zero water availability on 1 October.

Figure 4 shows the Crop Area Planting Decision function comparison used in WSP, Current Conditions (CC110) and survey based estimates. This figure shows that the Lachlan irrigators are not taking as much risk as they used to such as in late 1990s (WSP). This is consistent with what has been observed through allocations and diversions over the last few years. The reason of recent conservatism may be due to the fact that Lachlan recorded its worst ever drought in 2000s and a number of irrigators found it very difficult to survive economically. Since the break of drought they have started using their allocations very cautiously so that they can survive through future droughts.

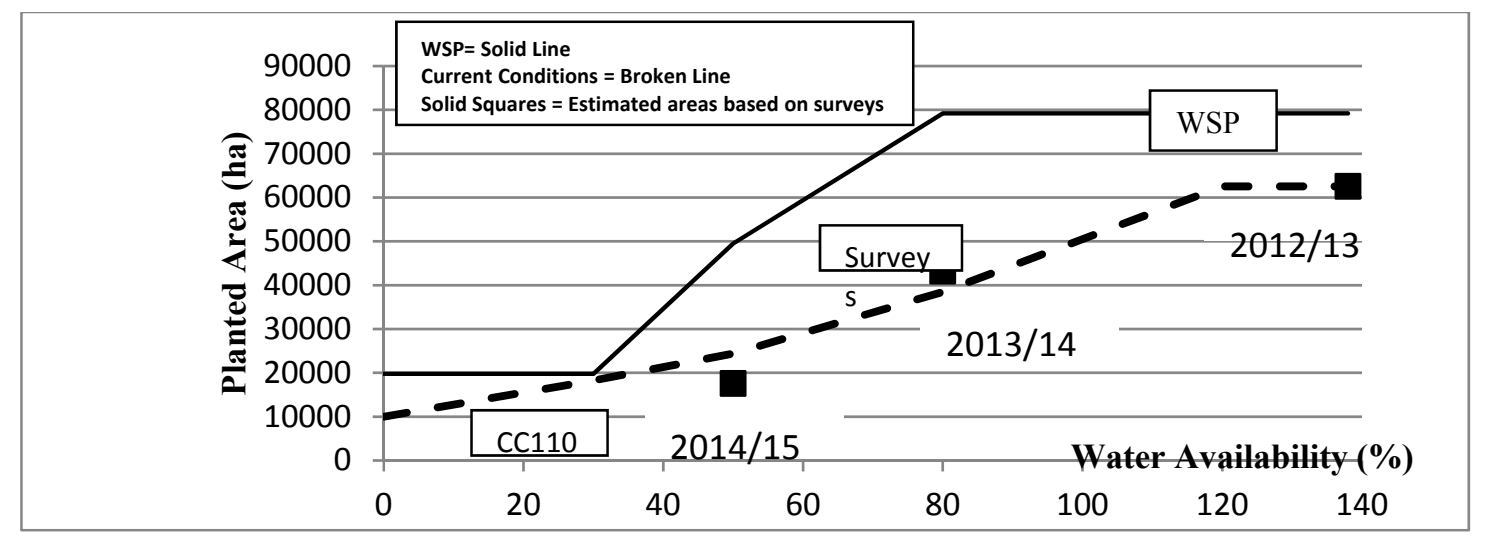

Figure 4. Derivation of Crop Area Planting Decision for Current Conditions model

\section{DEVELOPMENT OF CURRENT CONDITIONS MODEL}

IQQM model was configured to represent "Current Conditions" by updating the planted crop types and areas and Crop Area Planting Decision. The licensing conditions and entitlement along with any infrastructure changes were also incorporated in the model. The newly developed model was then subjected to various statistical as well as visual tests to check whether the results match the recorded data such as diversions, dam storage volumes and end of system flows. Model was slightly overestimating diversions that needs further adjustments.

The newly developed Crop Area Planting Decision function discussed in previous section indicated that the irrigators are not taking excessive risks and therefore as expected the valley diversions over 115 years model simulation reduced significantly compared to WSP. Based on model result the use limit was revised from $75 \%$ to $100 \%$.

\section{CONCLUSIONS}

This study details various challenges encountered in developing the Current Conditions IQQM model of Lachlan River System of NSW. A 3 to 5 years of farm data such as crop types and planted areas are needed to configure the model to represent the most recent conditions. In addition reliable diversion data for each entitlement holder is a must for the estimation of planted crop areas. Annual irrigator surveys provide more reliable statistics but it is a cumbersome process. Remote sensing based method may be a promising alternative. However, future satellite imagery based predictions require a good calibration of remote sensing parameters to at least 3-4 years of accurate recorded data. Once more data are available, the procedure described in this paper needs to be improved further. Based on Current Condition model scenario, the Lachlan use limit was revised upwards from $75 \%$ to $100 \%$.

\section{REFERENCES}

DLWC (1995). Integrated Quantity-Quality Model (IQQM), Reference Manual. DLWC Report No. TS94.048, Parramatta, NSW.

Hameed, T. and Podger, G. (2001). "Use of IQQM simulation model for planning and management of a regulated river system", IAHS Red Book 2001, pp 83-89.

Hughes, R.M., Shaikh, M., Hameed, T and Smith, G. (2015). Spatially Define Surface Water Irrigated Area by IQQM Reach: Lachlan Valley Pilot Study, Department of Primary Industries - Water Report, Parramatta, NSW 